\title{
DiVERSIDAD MORFOLÓGICA DEL ANDROCEO Y GINECEO DE 17 especies de Papilionoideae (F ABACEAE) NATIVAS DEL Valle de Lerma (Salta-Argentina) y su Relación CON ALGUNOS ASPECTOS REPRODUCTIVOS
}

\author{
MORPHOLOGICAL DIVERSITY OF ANDROECIUM AND GYNOECIUM OF 17 \\ Papilionoldeae (FABAceae) species native to Lerma Valley (Salta- \\ ARgentina) AND ITS RELATIONS TO REPRODUCTIVE ASPECTS
María Mercedes Alemán ${ }^{1,2, *}$ (D) Diego López-Spahr ${ }^{1,2}$ (D) Carlos Gómez ${ }^{2,3}$ (D) y Carolina Yañez ${ }^{1}$ D

1. Laboratorio de Histología y Anatomía de Plantas, Facultad de Ciencias Naturales, Universidad Nacional de Salta (UNSa), Avenida Bolivia 5150, 4400 Salta, Argentina. 2. Sede Regional Metán-Rosario de la Frontera, UNSa, Coronel Vidt 346, Metán, 4440, Salta, Argentina. 3. Laboratorio de Microscopía Electrónica de Barrido (LASEM), UNSa, Avenida Bolivia 5150, 4400, Salta, Argentina.

*mercialem@yahoo.com.ar

Citar este artículo

ALEMÁN, M. M., D. LÓPEZSPAHR, C. GÓMEZ y C. YAÑEZ. 2020. Diversidad morfológica del androceo y gineceo de 17 especies de Papilionoideae (Fabaceae) nativas del Valle de Lerma (SaltaArgentina) y su relación con algunos aspectos reproductivos. Bol. Soc. Argent. Bot. 55: 369-387.

DOI: https://doi. org/10.31055/1851.2372.v55. n3.27867

Recibido: 10 Marzo 2020 Aceptado: 22 Mayo 2020 Publicado: 30 Septiembre 2020 Editora: Ana María Gonzalez (D)

ISSN versión impresa 0373-580X ISSN versión on-line 1851-2372

\section{SUMmARY}

Background and aims: The species of Papilionoideae have floral traits or strategies related to the pollination mechanisms and promote cross pollination such as mechanic barriers, spatial or temporal separation of the maturation of the sexual organs, among others. The aim of this study was to provide a detailed morphological description of the androecium and gynoecium of 17 Papilionoideae species native to Lerma Valley (Salta-Argentina).

M\&M: We studied on field and laboratory quantitative and qualitative floral traits and analized from a functional point of view those traits that could be related to the reproductive system and to the pollination mechanisms.

Results: Most of the species are homogamous and have monadelphous or pseudomonadelphous with basal fenestration androecium, monomorphic anthers, variable forms of the style and stigma, stylar trichomes, peristigmatic trichomes and stigmatic membrane. We registered for the first time some traits in some of the species, such as the spontaneous rupture of the stigmatic membrane during the anthesis and the reduction of anthers-stigma distance after the maturation of both sexual organs.

Conclusions: All the studied species have floral traits associated with a reduction in selfpollination. Detailed information on morphology and other traits of the androecium and gynoecium has been obtained, and could be used to describe better their pollination mechanisms and to understand some aspects of their reproductive biology.

\section{KEY WORDS}

Androecium, floral biology, gynoecium, reproduction, pollination mechanism, Papilionoideae.

\section{RESUMEN}

Introducción y objetivos: Las especies de Papilionoideae presentan características florales o estrategias relacionadas con los mecanismos de polinización y que favorecen la polinización cruzada como la presencia de barreras físicas, la separación espacial o temporal en la maduración de los ciclos fértiles, entre otras. El objetivo de este trabajo fue brindar una descripción detallada de la morfología del androceo y gineceo de 17 especies de Papilionoideae nativas del Valle de Lerma (Salta-Argentina).

M\&M: Se estudiaron a campo y en laboratorio características florales cuantitativas y cualitativas y se analizaron desde un punto de vista funcional aquellas características que estarían relacionadas con el sistema reproductivo y los mecanismos de polinización.

Resultados: La mayoría de las especies son homógamas, presentan androceo monadelfo o pseudomonadelfo con fenestras basales, anteras monomórficas, formas variables del estilo y del estigma, tricomas estilares y periestigmáticos y membrana estigmática. Se describe por primera en algunas especies la ruptura espontánea de la membrana estigmática en la antesis y la reducción de la distancia anteras estigma luego de la maduración de los ciclos sexuales.

Conclusiones: Todas las especies estudiadas presentan características florales asociadas a la reducción de la autopolinización. Se obtuvo información detallada sobre la morfología y otras características del androceo y gineceo que podría ser utilizada para describir mejor sus mecanismos de polinización y para comprender aspectos de su biología reproductiva.

\section{Palabras clave}

Androceo, biología floral, gineceo, mecanismo de polinización, Papilionoideae, sistema reproductivo. 


\section{INTRODUCCIÓN}

La diversidad de formas y función de las flores ha sido asociada con la amplia variedad de estrategias de cruzamiento y el sistema sexual de una planta (Barret, 2002). Las plantas que tienen flores hermafroditas (i.e. que presentan los dos sexos en la misma flor) tienen la posibilidad de autopolinizarse o de presentar polinización cruzada, la ocurrencia de una u otra va a depender de las características morfológicas (Barret, 2010) o de características fisiológicas de la flor (Franklin -Tong, 2008). Numerosas especies con flores hermafroditas, han desarrollado estrategias que han sido interpretadas como características para evitar la autopolinización, e indirectamente evitar la depresión por endogamia que se encuentra vinculada a este tipo de reproducción (Barret, 2002). Entre dichas características se encuentran la presencia de membrana estigmática, tricomas periestigmáticos y estrategias como la hercogamia y la dicogamia entre otras. Todas estas características florales favorecen la polinización cruzada, evitando la interferencia entre las funciones masculina y femenina (Lloyd \& Webb, 1986; Webb \& Lloyd, 1986; Barrett, 2002).

Un modelo de flor donde se pueden analizar estas características es la flor de la familia Fabaceae que es generalmente hermafrodita. Asimismo, existen especies con flores diclinas o unisexuales (con solo androceo o gineceo en la flor) representadas en las seis subfamilias (sensu LPWG, 2017; Tucker, 1988a, 1988b, 1990, 1991, 1992; Grünmeyer, 1990; Ulibarri, 2008; Hoc et al., 1994). Las Papilonoideae (Leguminoseae) presentan una arquitectura floral en la cual el androceo y el gineceo se encuentran dentro de una unidad formada por los pétalos de la quilla y las alas. Los polinizadores que visitan estas flores deben ejercer una fuerza tal que permita mover el complejo alas-quilla para poder acceder a las recompensas florales, y así polinizar la flor. Esto se conoce como mecanismo de polinización y se sabe que es accionado principalmente por abejas (Arroyo, 1981; Westerkamp, 1997; Etcheverry et al., 2008; Galloni et al., 2008; Figueroa Fleming \& Etcheverry, 2017). En adición, la mayoría de las Fabaceae, sobre todo las especies de la subfamilia Papilionoideae (aprox. 80\%) son autocompatibles, por lo que muchas especies de este grupo pueden desarrollar frutos y semillas por autopolinización
(Arroyo, 1981). Por otra parte, la autopolinización en las mismas puede ser evitada por la presencia de una autoincompatibilidad fisiológica, por dicogamia o por barreras mecánicas presentes en las flores (Arroyo, 1981; Yeo, 1993; Suzuki, 2003; Galloni et al., 2007).

En las Papilionoideae el androceo es pentámero con 9-10 estambres que se ubican en dos verticilos que alternan entre sí (Polhill et al., 1981; LPWG, 2017). En algunos géneros se han registrado diferencias entre los estambres de ambos verticilos en cuanto a tamaño, forma, unión de los filamentos y período de dehiscencia (Polhill et al., 1981; Rodríguez-Riaño et al., 1999b). Existe una tendencia a la fusión de los filamentos del androceo, formando un tubo de diez estambres (androceo monadelfo), o bien los nueve estambres se fusionan dejando el décimo libre (androceo diadelfo; Arroyo, 1981; Rodríguez-Riaño et al., 1999b; Tucker, 2003). También se ha descrito la pseudomonadelfia, en este caso el androceo es diadelfo y al final del desarrollo el filamento del estambre libre se une a los adyacentes generalmente a través de una fusión superficial de sus márgenes, y deja o no un par de orificios o ventanas (fenestras) en la base (Tucker, 1987, 1989, 2003; Rodríguez-Riaño et al., 1999b). Generalmente, el tipo de androceo está relacionado con la presencia o ausencia de nectarios intraestaminales, así las especies nectaríferas presentan un androceo diadelfo o pseudomonadelfo con fenestras basales (Tucker, 1987; López et al., 1999; Rodríguez-Riaño et al., 1999b; Agostini \& Sazima, 2006). Mientras que el androceo monadelfo y pseudomonadelfo sin fenestras basales, está presente en especies cuyas flores carecen de nectarios (Rodríguez-Riaño et al., 1999b).

El gineceo es súpero y unicarpelar excepto en la tribu Swartzieae, que presenta flores con gineceo pluricarpelar (Polhill et al., 1981; RodríguezRiaño et al., 1999a; Tucker, 2003), variando en forma, tamaño y otras características. El ovario puede ser recto o curvado, articulado o no, glabro o pubescente, sésil o con un corto estipe en la base (López et al., 1999; Rodríguez-Riaño et al., 1999a). La forma del estilo varía en un amplio rango desde lineal, lineal-curvado en el ápice o en la base, enrollado o con rotación. La presencia de diversos indumentos en el estilo y estigma es un carácter común entre las especies de Papilionoideae 


\section{M. Alemán et al. - Diversidad de androceo y gineceo de especies de Papilionoideae}

(Tucker, 2003), así el estilo puede ser glabro o con tricomas. Cuando los tricomas están dispuestos hacia la porción distal, y son uniformes con respecto a la forma, orientación y densidad, se considera que el gineceo presenta un cepillo estilar (Lavin \& Delgado, 1990). Éste puede tener diferentes posiciones: dorsal o extrorso, ventral o introrso, y en algunos casos está dispuesto en ambas superficies. El estigma de la mayoría de las Papilionoideae se caracteriza por presentar papilas pequeñas a medianas, con o sin membrana cuticular. Frecuentemente está rodeado de tricomas cortos (estigma ciliado) o largos (estigma penicilado; Lavin \& Delgado, 1990). La forma del estilo y del estigma y la presencia del cepillo estilar han sido utilizados como caracteres de importancia filogenética en las Papilionoideae (Polhill et al., 1981; Lavín \& Delgado, 1990; Rodríguez-Riaño et al., 1999a).

Los caracteres descritos anteriormente, como la forma de las anteras, del estilo y el estigma y la presencia de indumentos sobre los mismos han sido relacionados con los mecanismos de polinización. Algunos autores vinculan los mecanismos de polinización de las Papilionoideae con una mayor eficiencia en la transmisión de polen desde la planta a los polinizadores y de estos al estigma de la flor (Arroyo, 1981; Rodríguez-Riaño et al., 1999a). Otros proponen que constituyen características funcionales o barreras mecánicas para evitar la autopolinización (Galloni et al., 2008; Aronne et al., 2012). Por ejemplo, la presencia de una membrana estigmática permite que el polen se adhiera y se hidrate para poder germinar una vez que ésta se desprende cuando el estigma está receptivo en la antesis y/o se rompe por fricción durante la visita de los polinizadores (HeslopHarrison \& Heslop-Harrison, 1985; Yeo, 1993; Drewes \& Hoc, 2000; Faigón Soverna et al., 2003; Etcheverry et al., 2003; Drewes, 2005; Basso Alves et al., 2011; Alemán et al., 2014). También se ha sugerido que el estigma ciliado y penicilado actúan como barreras físicas para la autopolinización (Hoc \& Amela García, 1999; Lavin \& Delgado, 1999; Galloni et al., 2007; Bystricky et al., 2010; Drewes \& Gamba, 2011; Basso Alves et al., 2011; Alemán et al., 2014), mientras que el cepillo estilar estaría involucrado en la presentación secundaria de polen (Lavín \& Delgado, 1990) y en el mecanismo de polinización citado en algunos géneros de
Phaseolus, Macroptilium y Cochliasanthus (Hoc et al., 1993, 2003; Hoc \& Amela García, 1999; Etcheverry et al., 1999, 2008, 2012). A su vez, la autopolinización en las mismas puede ser evitada por autoincompatibilidad, por dicogamia o por barreras mecánicas comúnmente asociadas a la actividad de forrajeo de los polinizadores (Arroyo, 1981; Yeo, 1993; Suzuki, 2003; Galloni et al., 2007). En el caso de Cochliasanthus caracalla (Etcheverry et al., 2008) se encontró que la autogamia era menor en aquellas poblaciones con separación marcada de ambos ciclos, mayor longitud de tricomas peri-estigmáticos y estilares, mientras que en otras poblaciones donde estas variables mostraron valores reducidos, la autogamia resultaba más exitosa.

En este contexto, el presente trabajo busca ampliar el conocimiento existente sobre la morfología floral de las Papilionoideae analizando el androceo y gineceo de especies que aún no fueron estudiadas con tanto detalle. Para ello se analizaron 17 especies pertenecientes a nueve géneros de Papilionoideae nativas del valle de Lerma (Salta), desde el punto de vista morfológico y funcional, a fin de generar información de base que permita entender algunos aspectos de los mecanismos de polinización y el modo de reproducción de estas especies. El presente trabajo complementa estudios previos de morfología floral en este mismo grupo de especies (Alemán et al., 2017).

\section{Materiales Y MÉtodos}

\section{Sitio de estudio y especies estudiadas}

El estudio se realizó en el noroeste del Valle de Lerma, Provincia de Salta, Argentina (2434'53"$25^{\circ} 31^{\prime} 38^{\prime \prime} \mathrm{S}$ y $\left.65^{\circ} 22^{\prime} 30^{\prime \prime}-65^{\circ} 39^{\prime} 70^{\prime \prime} \mathrm{O}\right)$. La vegetación corresponde a la transición entre el bosque lluvioso de las Yungas y el bosque seco del Chaco (Cabrera, 1976). Existe una fuerte estacionalidad en el área, con lluvias concentradas entre noviembre y mayo. La precipitación media anual es de $662.58 \mathrm{~mm}$ (Bianchi \& Yáñez, 1992) y la temperatura media anual es de $17.55^{\circ} \mathrm{C}$ (Bianchi, 1996).

Las especies estudiadas pertenecen a cinco tribus de la subfamilia de Papilionoideae: Crotalarieae (APG, 2019): Crotalaria chaco-serranensis H. Bach \& Fortunato, C. pumila Ortega, C. stipularia 
Desv.; Dalbergieae: Zornia contorta Mohlenbr.; Desmodieae: Desmodium incanum DC., D. pachyrrhizum Vogel, D. subsericeum Malme, D. uncinatum (Jacq.) DC.; Indigofereae: Indigofera parodiana Burkart, I. suffruticosa Mill.; Phaseoleae: Cologania broussonetii (Balb.) DC., Galactia latisiliqua Desv., Macroptilium erythroloma (Mart. ex Benth.) Urb., M. gibbosifolium (Ortega) A. Delgado, Phaseolus vulgaris L. var. aborigineus (Burkart) Baudet, Rhynchosia edulis Griseb., R. minima (L.) DC. Los ejemplares herborizados que documentan el presente estudio se encuentran depositados en el Herbario MCNS (Museo de Ciencias Naturales Salta).

\section{Características cualitativas de androceo y gineceo}

Para cada especie, 10 flores en antesis provenientes de 10 individuos diferentes fueron colectadas y conservadas frescas en un recipiente hermético hasta su análisis en el laboratorio dentro del mismo día. Las mismas fueron observadas en lupa a fin de determinar: concrescencia de filamentos, forma de anteras del verticilo interno $\mathrm{y}$ externo, inserción de anteras en los filamentos de ambos verticilos, forma de estilo. Se utilizó una flor de cada especie para hacer dibujos con cámara clara. Para estudiar las características micromorfológicas (presencia de cepillo estilar, de tricomas periestigmáticos, tipo de estigma, presencia y aspecto de la membrana estigmática) se recogieron otras 10 flores en antesis y 10 botones florales (de 10 individuos diferentes) de cada especie, y se fijaron en solución de glutaraldehído al 2,5\%. Las flores y botones florales fijados fueron deshidratados con una serie creciente de alcoholes, secados por punto crítico con $\mathrm{CO}_{2}$, posteriormente bañados con oro (D’Ambrogio de Argüeso, 1986) y finalmente se tomaron microfotografías en un Microscopio Electrónico de Barrido (MEB) JEOLJSM 5480 LV. En todos los casos se consideró como posición ventral o introrsa aquella que se orienta hacia el estandarte o vexilo y dorsal o extrorsa a aquella que se orienta hacia la quilla.

\section{Características cuantitativas de androceo y gineceo}

Las medidas se realizaron con calibre digital, ayudado por un microscopio estereoscópico, en 10 flores frescas en antesis (de 10 individuos diferentes) de cada especie. Las variables medidas fueron: longitud del tubo estaminal, ancho del tubo estaminal, longitud de los estambres de cada verticilo, distancia entre el estambre más largo y más corto, longitud del gineceo y longitud del estilo. La longitud de los tricomas del cepillo estilar y los tricomas periestigmáticos se midieron en microscopio estereoscópico con un software de procesamiento de imágenes (Motic Image Plus 1.2).

Características asociadas al mecanismo de polinización y sistema reproductivo

La receptividad estigmática se determinó en otros 10 botones florales y 10 flores en antesis (de 10 individuos diferentes) de cada especie mediante la técnica del peróxido de hidrógeno (Kearns \& Inouye, 1993). La dehiscencia de las anteras fue registrada mediante observaciones a campo en 25 botones florales y 25 flores recién abiertas de al menos 10 individuos diferentes con la ayuda de una lupa de mano (Dafni, 1992). En el caso de las especies del género Crotalaria se realizó una observación adicional en otras 25 flores el día siguiente a la apertura floral. La manipulación de las flores se realizó cuidadosamente evitando alterar la disposición de las piezas. Se consideró como homógamas a aquellas cuya receptividad estigmática coincidió con la dehiscencia de las anteras y dicógamas a aquellas en las que no era coincidente (Lloyd \& Webb, 1986). En todas las observaciones se registró, además, si la presentación de los granos de polen para los polinizadores era primaria (los granos de polen están disponibles en las anteras) o secundaria (disponibles en otras partes de la flor; Yeo, 1993).

Para cada especie se realizaron observaciones focales de 30 minutos, dos veces al día a la mañana y a la tarde, desde el inicio hasta el final de la antesis. En cada observación se registró si el visitante tomaba contacto o no con los ciclos reproductivos de la flor. Se consideró como polinizadores a aquellos visitantes capaces de activar el mecanismo de polinización y tomar contacto con los ciclos reproductivos de la flor. Además, en cada observación se registró qué parte de los ciclos reproductivos tomaba contacto con el cuerpo del polinizador (anteras, estigma, cepillo estilar) y en qué parte del cuerpo se depositaban los granos de polen (esternotribo: parte ventral del polinizador; nototribo: parte dorsal; pleurotribo: parte lateral). La identidad de los polinizadores no se informa en este trabajo. Sin embargo, todos los taxones registrados 


\section{M. Alemán et al. - Diversidad de androceo y gineceo de especies de Papilionoideae}

como polinizadores para este grupo de especies son Himenópteros (Figueroa Fleming, 2014).

Para determinar si la membrana estigmática tiene ruptura espontánea o no, se marcaron 10 botones florales (de 10 individuos diferentes) de cada especie y se cubrieron con bolsas de voile para evitar los polinizadores. El día posterior a la antesis fueron colectadas, diseccionadas y analizadas a nivel del estigma a través del MEB, siguiendo la metodología descrita anteriormente.

Para definir la existencia de una separación espacial entre las anteras y el estigma (hercogamia) se colectaron 30 flores en estadio de botón floral y 30 flores recién abiertas de cada especie tomadas al azar de al menos 10 individuos diferentes, que luego se diseccionaron bajo lupa y se midió la distancia anteras-estigma con calibre digital.

\section{Análisis estadísticos}

A fin de comparar las medias de la longitud de los tipos de tricomas estilares se realizó una prueba $t$ de Student. Para evaluar si la distancia anteraestigma aumenta o disminuye entre el estadio de botón floral y flor abierta en una misma especie, se realizó una prueba $t$ de Student. Los datos fueron analizados con el programa INFOSTAT (2016).

\section{Resultados}

Características cualitativas y cuantitativas de androceo y gineceo

Las características cualitativas estudiadas del androceo y gineceo, se resumen en la Tabla $1 \mathrm{y}$ las características cuantitativas se resumen en la Tabla 2. Todas las flores presentan el modelo típico de Papilionoideae con androceo y gineceo encerrados por la quilla (Fig. 1). En todas las especies el androceo presenta nueve estambres fusionados y un estambre vexilar (diadelfo y pseudomonadelfo) con la excepción de Zornia contorta (monadelfo). Sólo las especies de los géneros Crotalaria, Macroptilium y Phaseolus presentan tricomas estilares. Todas las especies presentan tricomas periestigmáticos formando un anillo completo, excepto $M$. erythroloma que los presenta solo en posición dorsal. Además, todas las especies presentan membrana estigmática, excepto las especies del género Crotalaria. A continuación, se realiza una descripción detallada de las características cualitativas del androceo (Fig. 2) y gineceo (Figs. 3-5) de las especies estudiadas:

Cologania broussonetii: El androceo está compuesto por nueve estambres fusionados desde la base hasta el $90 \%$ de su longitud, excepto el estambre vexilar (Fig. 2A). El ovario es pubescente, el estilo se observó recto la mayor parte, con una curvatura en la base (Fig. 3A) y es glabro (Fig. 4A). El estigma es de forma discoidal de posición apical rodeado de tricomas largos formando un anillo completo, con una membrana estigmática de superficie lisa (aspecto de velo; Fig. 5A).

Crotalaria chaco-serranensis, C. pumila, C. stipularia: En las tres especies estudiadas los filamentos de los nueve estambres están fusionados el $60 \%$ de su longitud y el estambre vexilar se encuentra unido por los bordes al resto de los estambres, formando un tubo estaminal. En la base del tubo se observó una curvatura que constituía la abertura para acceder al nectario (Fig. 2B). El ovario es pubescente con tricomas largos. El estilo es largo y delgado, en la base presenta una curvatura muy marcada hacia la parte ventral, formando un ángulo aproximado de $90^{\circ}-95^{\circ}$ con respecto al ovario (estilo geniculado; Fig. 3B). Las tres especies presentan tricomas estilares dispuestos en varias hileras o filas, en C. chaco-serranensis y C. pumila estos son introrsos (Fig. 4B-C), mientras que en $C$. stipularia el cepillo estilar describe un giro (levógiro) laxo de tal manera que se observaron algunos tricomas en la parte dorsal (Fig. 4D). El estigma es globoso de posición introrso en C. chacoserranensis y $C$. stipularia (Fig. 5B) mientras que en $C$. pumila es apical o terminal (Fig. 5D). Las tres especies presentan tricomas periestigmáticos formando un anillo completo cuya longitud varía de acuerdo a la posición de los mismos (Fig. 5D). Se encontraron diferencias significativas entre la longitud de los tricomas periestigmáticos introrsos y extrorsos en todas las especies (C. stipularia: $\mathrm{T}=$ 5.89, $\mathrm{P}=0.0001 ;$ C. chaco-serranensis: $\mathrm{T}=2.75, \mathrm{P}$ $=0.02 ;$ C. pumila: $\mathrm{T}=2.13, \mathrm{P}=0.05)$. En todas las especies la superficie estigmática estaba compuesta por papilas epidérmicas, no se observó membrana estigmática (Fig. 5C).

Desmodium incanum, D. pachyrrhizum, D. subsericeum, D. uncinatum: En las cuatro especies estudiadas los filamentos de los nueve estambres están fusionados un $70 \%$ de su longitud. El estambre vexilar se encuentra unido por los bordes 


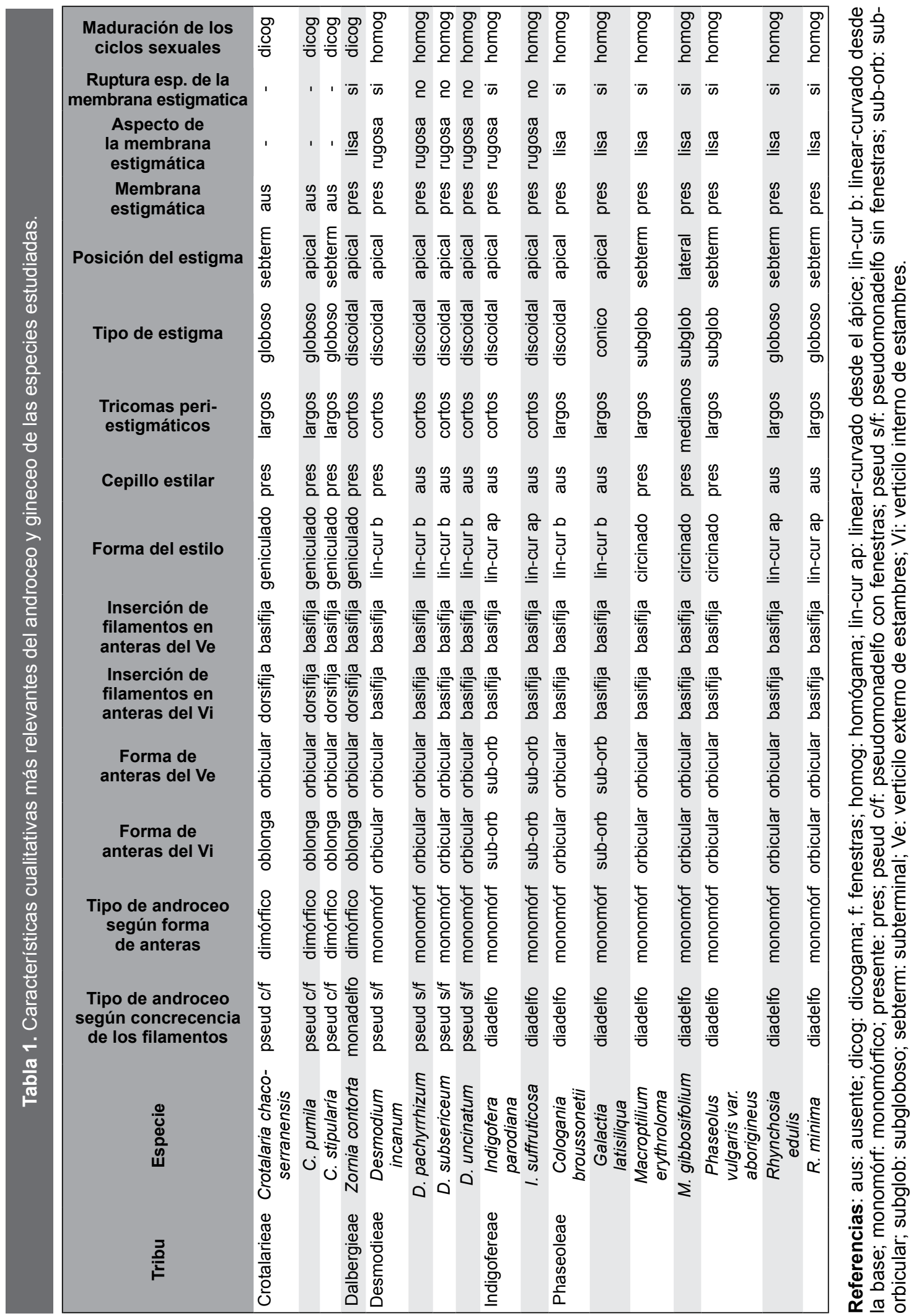




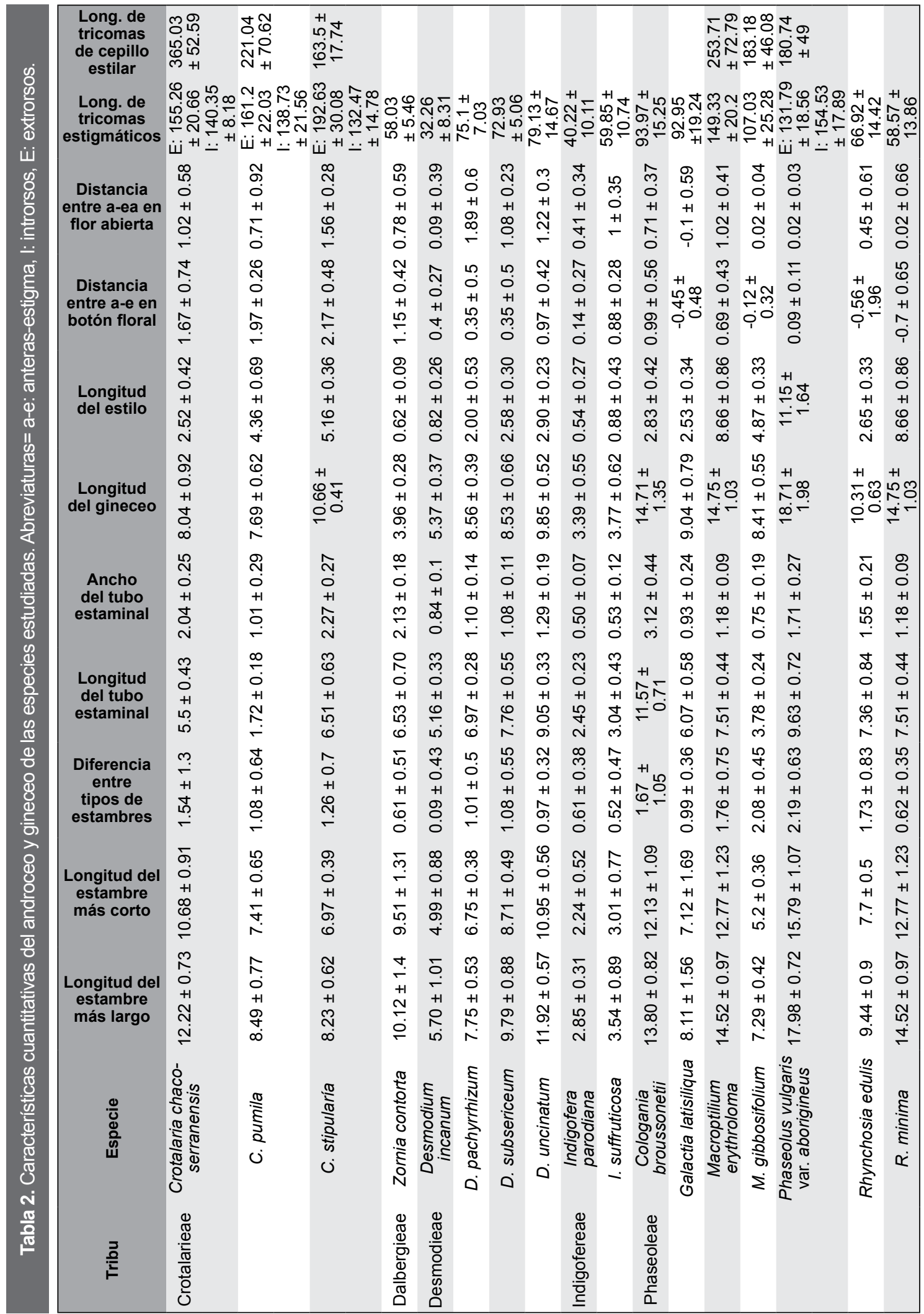




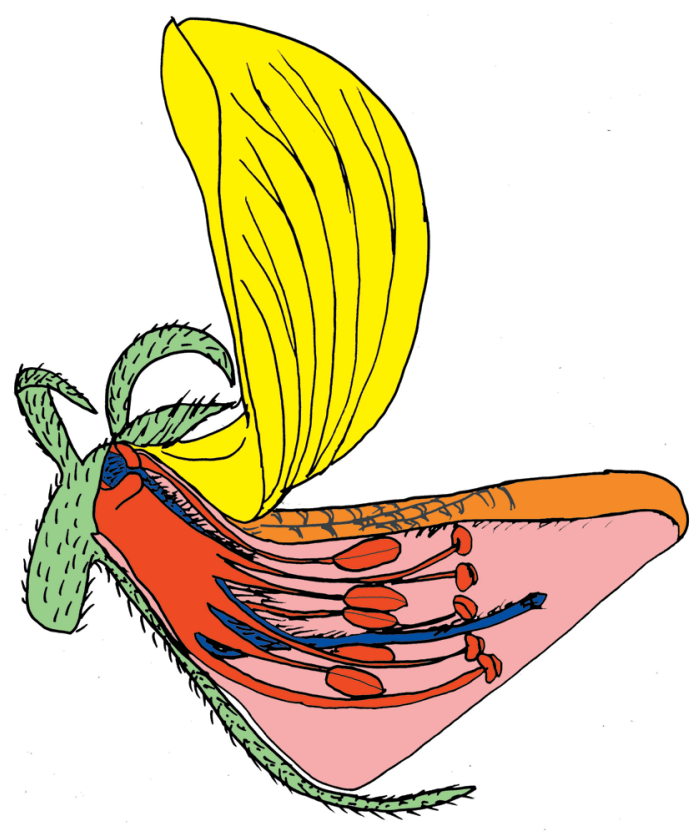

Fig. 1. Vista esquemática de una flor típica de Papilionoideae mostrando la ubicación de las piezas florales. La ilustración corresponde a Crotralaria chaco-serranensis. Colores $=$ verde: cáliz, amarillo: vexilo, naranja: ala, rosa: quilla, rojo: androceo, azul: gineceo.

al resto de los estambres solo en la base, formando un tubo estaminal, excepto en $D$. uncinatum donde esa unión se observó en un $70 \%$ de su longitud. En todos los casos la unión entre el estambre vexilar $\mathrm{y}$ el resto de los estambres es superficial (Fig. 2C). El ovario es pubescente. El estilo es corto y glabro (Fig 4E), curvado hacia el estandarte en la porción basal y levemente engrosado en esa zona, y recto en la porción apical (Fig. 3C). El estigma es discoidal de posición apical, rodeado de tricomas cortos formando un anillo periestigmático completo. El estigma de las cuatro especies presenta una membrana de superficie rugosa (aspecto de costra; Fig. 5E).

Galactia latisiliqua: Presenta los filamentos de los nueve estambres fusionados el $90 \%$, mientras que el estambre vexilar se encuentra libre (Fig. 2D). El ovario es pubescente con tricomas cortos, el estilo largo y delgado curvado levemente (Fig. 3D), glabro (Fig. 4F). El estigma es cónico de posición apical, rodeado de tricomas largos formando un anillo periestigmático completo, con membrana estigmática de superficie lisa (aspecto de velo; Fig. $5 \mathrm{~F})$.

Indigofera parodiana, I. suffruticosa: Ambas especies presentan los filamentos de los nueve estambres fusionados un $60 \%$ de su longitud, formando un tubo, mientras que el estambre vexilar se encuentra libre (Fig. 2E). El ovario es pubescente. El estilo es corto y robusto, levemente curvado hacia el estandarte en la porción apical (Fig. 3E), glabro (Fig. 4G). El estigma es discoidal de posición apical y rodeado de tricomas cortos formando un anillo periestigmático completo. En ambas especies se observó la presencia de una membrana estigmática de superficie rugosa (aspecto de costra; Fig. 5G).

Macroptilium erythroloma, M. gibbosifolium: Ambas especies presentan los filamentos de los estambres fusionados desde la base hasta un $60 \%$ formando el tubo estaminal, mientras que el estambre vexilar se encuentra libre (Fig. 2F). El ovario es pubescente. El estilo es largo y delgado con una leve torsión sobre su propio eje hacia la izquierda en la porción apical. Además, se observó que es aplanado dorsiventralmente en esta zona (Fig. 3F). En la parte distal presenta un cepillo estilar ventral o introrso que acompaña el levógiro, debajo de esta zona presenta una región engrosada del estilo (Fig. 4H). El estigma en $M$. gibbosifolium es terminal, subgloboso, de posición lateral, con tricomas periestigmáticos formando un anillo completo (Fig. $5 \mathrm{H})$. El estigma de $M$. erythroloma es subterminal, subgloboso, semicircular en la mitad inferior y triangular en la mitad superior (Fig. 5I), ubicado en posición ventral, con tricomas periestigmáticos solo en posición ventral. En ambas especies se observó la presencia de membrana estigmática de superficie lisa (aspecto de velo; Fig. 5I).

Phaseolus vulgaris var. aborigineus: Presenta los filamentos de los estambres fusionados desde la base hasta un $60 \%$ de su longitud, y el estambre vexilar se encuentra libre (Fig. 2G). El ovario es pubescente. El estilo es cilíndrico, alargado y robusto, doblado superiormente sobre sí mismo describiendo una espiral completa, con un leve aplanamiento en el sector terminal donde comienza el estigma (Fig. $3 \mathrm{G})$. Presenta un cepillo estilar en la parte apical y en posición ventral, que describe un giro levógiro (Fig. 4I). El estigma es subterminal, subgloboso, de 
M. M. Alemán et al. - Diversidad de androceo y gineceo de especies de Papilionoideae

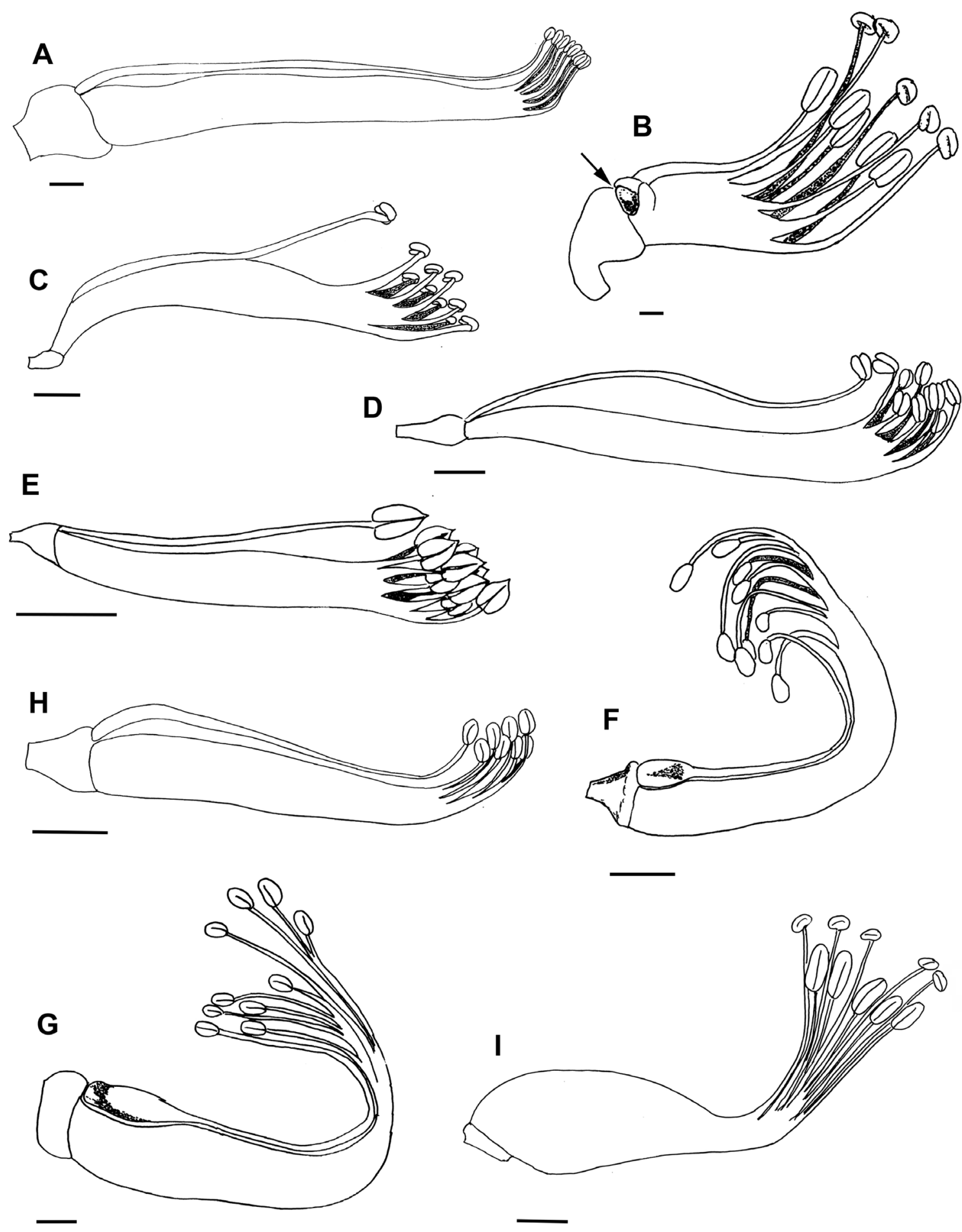

Fig. 2. Tipos de Androceo: A: Cologania broussonetii, B: Crotalaria chaco-serranensis, C: Desmodium subsericeum, D: Galactia latisiliqua, E: Indigofera suffruticosa, F: Macroptilium gibbosifolium, G: Phaseolus vulgaris var. aborigineus, H: Rhynchosia edulis, I: Zornia contorta. La flecha indica el acceso al nectario. Escalas: A, B, C, F, G = $1.2 \mathrm{~mm}, \mathrm{D}=1.6 \mathrm{~mm}, \mathrm{H}=2.5 \mathrm{~mm}, \mathrm{I}=2 \mathrm{~mm}, \mathrm{E}=3.2 \mathrm{~mm}$. 
A

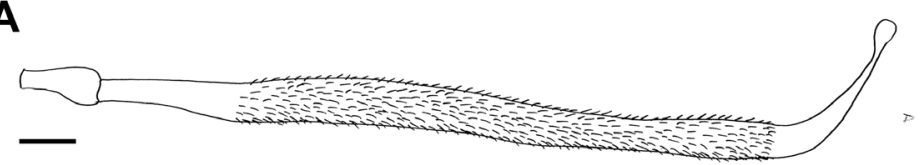

c

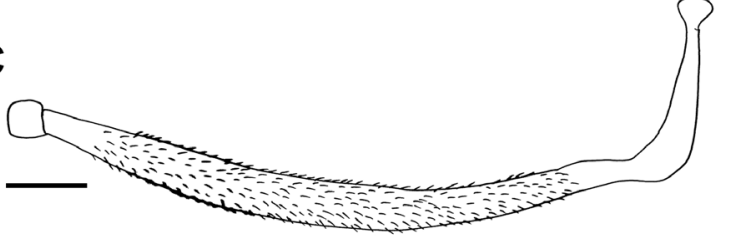

B
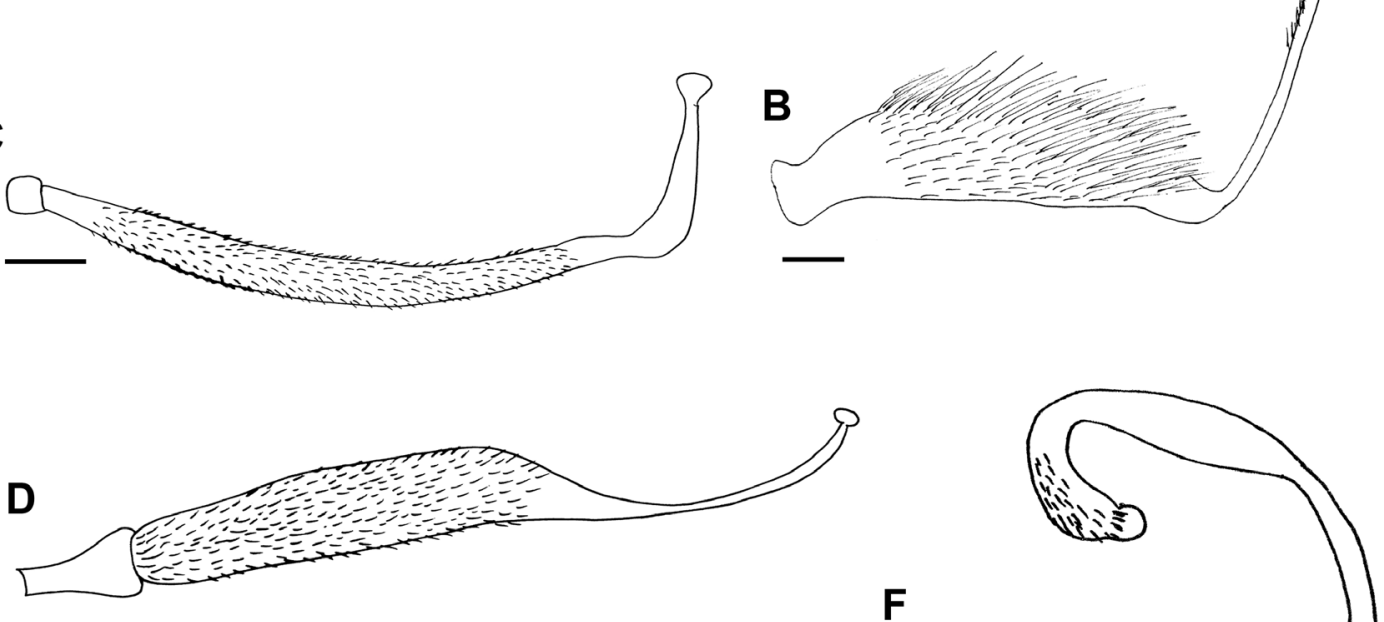

$\mathbf{F}$

E
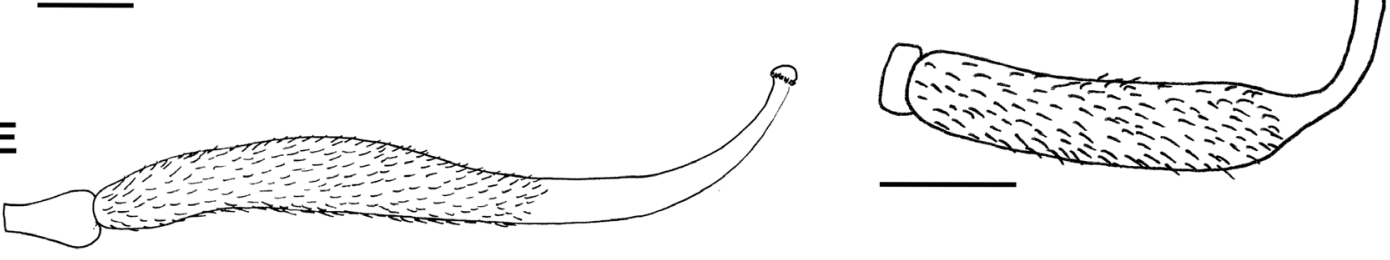

H

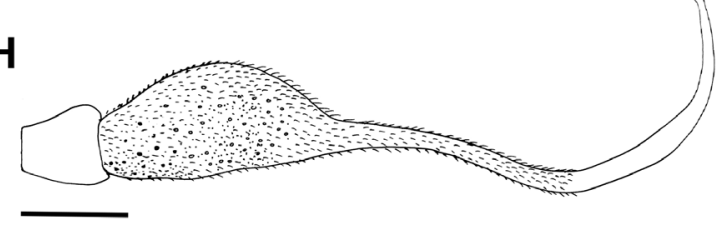

G
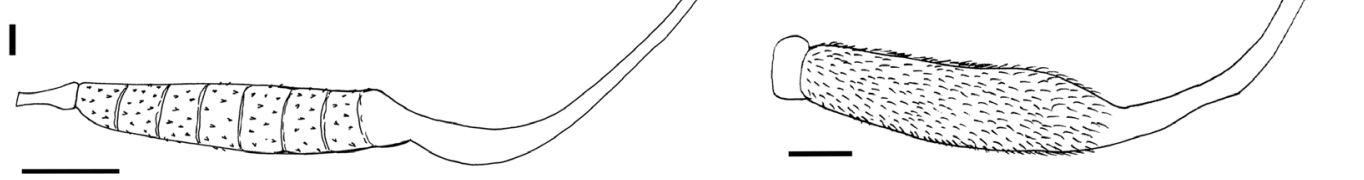

Fig. 3. Tipos de Gineceo: A: Cologania broussonetii. B: Crotalaria chaco-serranensis. C: Desmodium subsericeum. D: Galactia latisiliqua. E: Indigofera suffruticosa. F: Macroptilium gibbosifolium. G: Phaseolus vulgaris var. aborigineus. H: Rhynchosia edulis. I: Zornia contorta. Escalas: A, B, C, F, G =1.2 mm, D =1.6 $\mathrm{mm}, \mathrm{H}=2.5 \mathrm{~mm}, \mathrm{I}=2 \mathrm{~mm}, \mathrm{E}=3.2 \mathrm{~mm}$.

posición lateral, rodeado de tricomas dispuestos en varias filas. Se registraron diferencias significativas en la longitud de los tricomas introrsos y extrorsos
$(\mathrm{T}=-3.64, \mathrm{P}=0.004)$. Se observó la presencia de membrana estigmática de superficie lisa (aspecto de velo; Fig. 5J). 
M. M. Alemán et al. - Diversidad de androceo y gineceo de especies de Papilionoideae
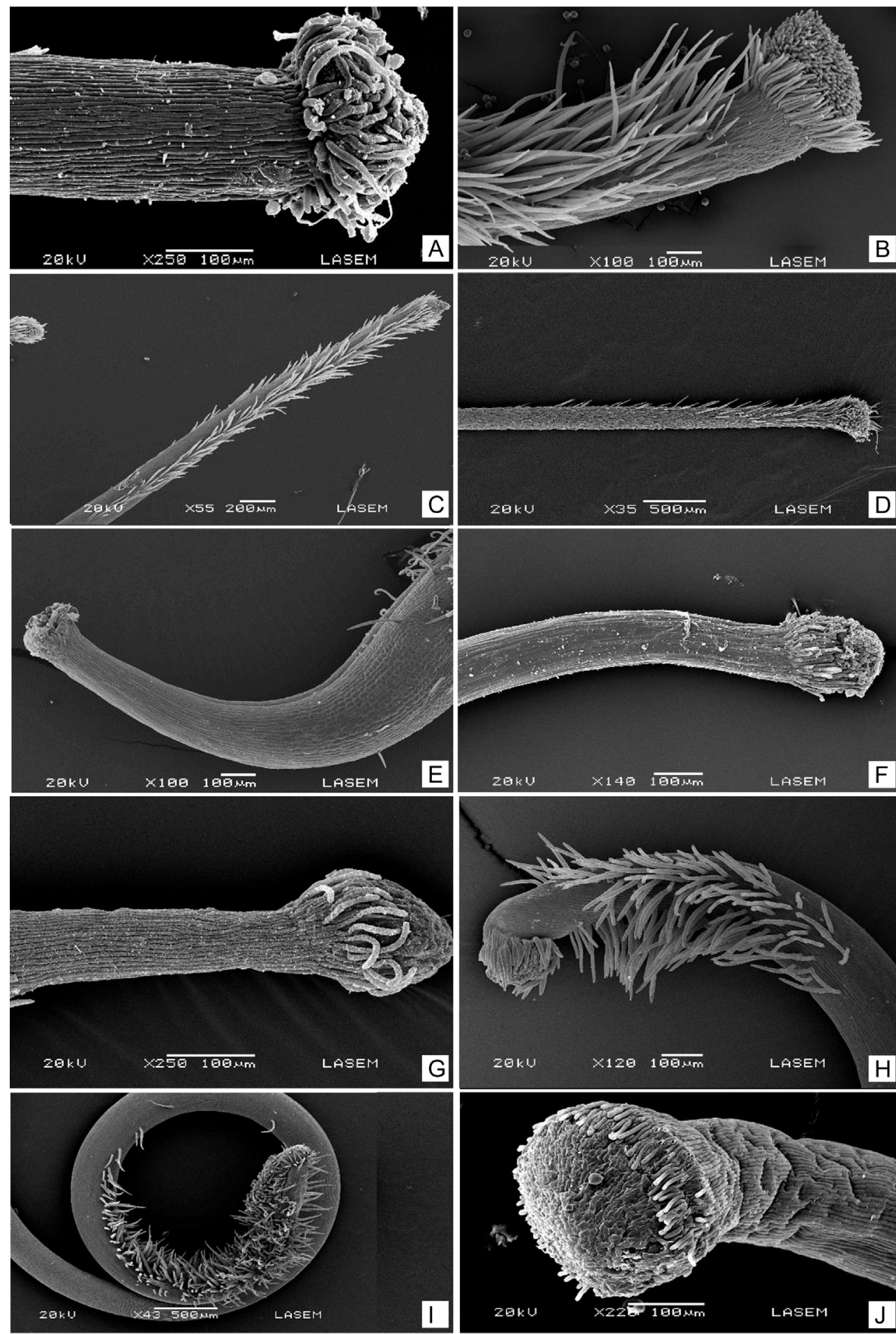

2Gku

LASEM

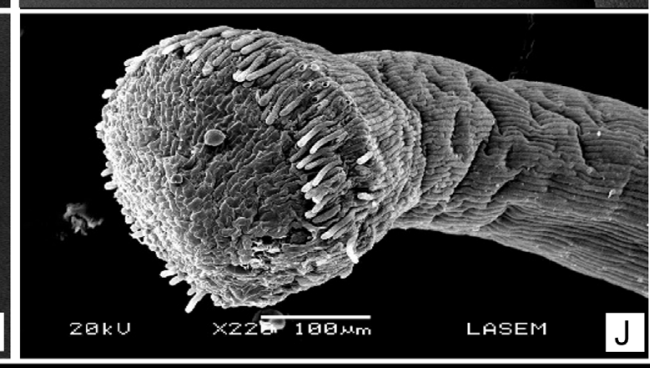

Fig. 4. Vista al MEB de los estilos. A: Cologania broussonetii. B: Crotalaria chaco-serranensis. C: C. pumila. D: C. stipularia. E: Desmodium subsericeum. F: Galactia latisiliqua. G: Indigofera suffruticosa. H: Macroptilium gibbosifolium. I: Phaseolus vulgaris var. aborigineus. J: Zornia contorta. 
Rhynchosia edulis, R. minima: En las dos especies los filamentos de los nueve estambres están fusionados desde la base hasta más de la mitad de su longitud, mientras que el estambre vexilar se encuentra libre (Fig. 2H). El estilo es largo, linear, curvado hacia el estandarte en la porción apical y glabro (Fig. 3H). El estigma es globoso, rodeado de tricomas largos formando un anillo periestigmático completo. En las dos especies estudiadas se observó la presencia de una membrana estigmática de superficie lisa (aspecto de velo; Fig.5K).

Zornia contorta: Los filamentos de los 10 estambres se hallan fusionados desde la base hasta un $60 \%$ de su longitud (Fig. 2I). El estilo glabro (Fig. $4 \mathrm{~J})$, largo y delgado, en la base presenta una curvatura muy marcada hacia la parte ventral, formando un ángulo aproximado de $135^{\circ}-140^{\circ}$ con respecto al ovario, y se encuentra engrosado en la zona donde se halla la curvatura (Fig. 3I). El estigma es discoidal de posición apical con tricomas periestigmáticos cortos. Se observó la presencia de membrana estigmática delgada de superficie lisa (aspecto de velo; Fig. 5L).

Características asociadas al mecanismo de polinización y sistema reproductivo

En C. broussonetii, G. latisiliqua, $R$. edulis y $R$. minima, se observó que la receptividad estigmática y la dehiscencia de las anteras ocurre en el estadío de botón floral (i.e. homógamas) y el polen tiene presentación primaria. Durante la activación del mecanismo las anteras y el estigma toman contacto con el cuerpo del polinizador y el polen se deposita en forma esternotriba. En estas especies se observó que la membrana estigmática se rasga y desprende espontáneamente al final de la antesis en aquellas flores que no recibieron visitas de los polinizadores, a modo de ejemplo se presenta a $R$. edulis (Fig. $5 \mathrm{M}-\mathrm{N}$ ). Estas cuatro especies presentan hercogamia en estadio de botón floral y de flor abierta. Sólo $R$. minima presentó diferencias significativas en la distancia anteras-estigma entre el estadío de botón floral y flor abierta $(\mathrm{T}=2.64 ; \mathrm{P}=0.014)$.

En las especies de Desmodium e Indigofera, se observó que la receptividad estigmática y la dehiscencia de las anteras ocurre en el estadio de botón floral (i.e. homógamas). Se observó que algunas de las anteras (tres a cinco) están dehiscentes en estadio de botón floral, mientras que el resto están dehiscentes luego de la apertura floral. Los granos de polen se encuentran disponibles en las anteras, en el estilo, estigma y parte interna de los pétalos de la quilla (presentación primaria y secundaria). Durante la activación del mecanismo las anteras y el estigma toman contacto con el cuerpo del polinizador y el polen se deposita en forma esternotriba. En estas especies se registró que la membrana estigmática permaneció intacta hasta su senescencia. Sin embargo, en $D$. incanum e I. parodiana se pudo observar una ruptura en los bordes de la membrana (Fig. 5O-P). Estas cinco especies presentan hercogamia en estadio de botón floral y de flor abierta. Se encontraron diferencias significativas en la distancia antera-estigma entre el estadio de botón floral y de flor abierta en $D$. pachyrrhizum $(\mathrm{T}=6.85 ; \mathrm{P} \leq 0.0001)$, D. subsericeum $(\mathrm{T}=4.98 ; \mathrm{P}=0.0001)$ e I. parodiana $(\mathrm{T}=2.15 ; \mathrm{P}=$ $0.042)$.

En las especies de Macroptilium y en P. vulgaris var. aborigineus se observó que la receptividad estigmática y la dehiscencia de las anteras ocurre en el estadio de botón floral (i.e. homógamas). El polen se encuentra disponible en el cepillo estilar previo a la antesis (i.e. presentación secundaria). Durante la activación del mecanismo el estilo y el estigma toman contacto con el cuerpo del polinizador y el polen se deposita en forma pleurotriba. Se observó que la membrana estigmática se desprende espontáneamente al final de la antesis en aquellas flores que no recibieron visitas de los polinizadores. Estas tres especies presentan hercogamia en estadío de botón floral y de flor abierta. No se encontraron diferencias significativas en la distancia anteraestigma entre ambos estadios.

En C. chaco-serranensis, C. pumila y $C$. stipularia se registró que la receptividad estigmática ocurre al día siguiente de la apertura floral, mientras que en $Z$. contorta se produce al momento de la apertura floral. En todas estas especies se observó que la dehiscencia de las anteras de los diferentes verticilos ocurre en momentos diferentes. La dehiscencia de las anteras del verticilo externo (oblongas) ocurre durante el estadio de botón floral y la dehiscencia de las anteras del verticilo interno (orbiculares) durante la apertura flora. El polen se encuentra disponible en un espacio en el interior de la quilla ubicado en la zona apical de la misma y en el caso de las especies de Crotalaria, también en el cepillo estilar (presentación secundaria). Durante la activación del mecanismo el estigma toma contacto con el cuerpo del polinizador y el 

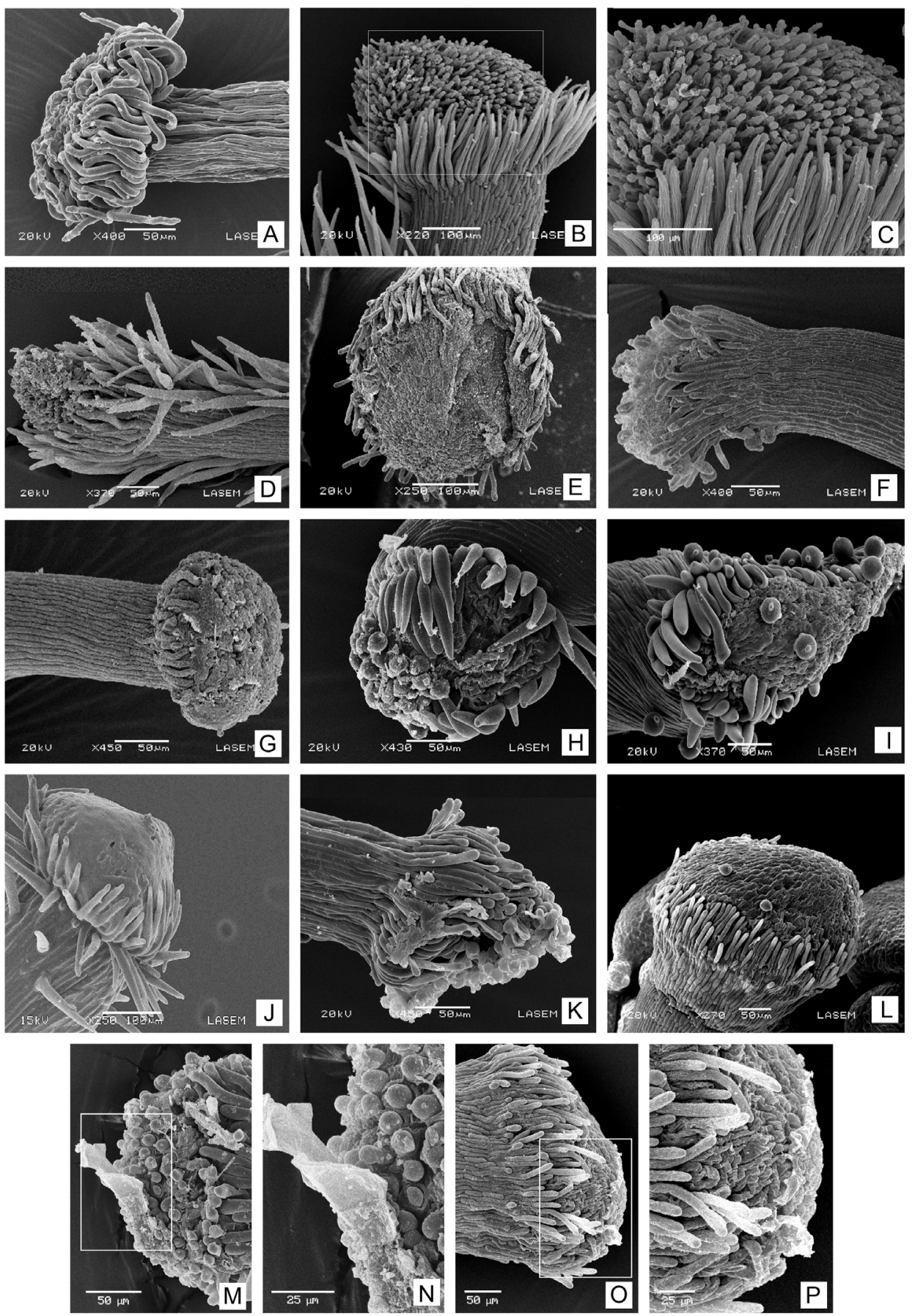

Fig. 5. Vista al MEB de los estigmas. A: Cologania broussonetii. B: Crotalaria chaco-serranensis. C: Detalle de B (estigma sin membrana, se observan las papilas estigmáticas). D: C. pumila. E: Desmodium subsericeum. F: Galactia latisiliqua. G: Indigofera suffruticosa. H: Macroptilium gibbosifolium. I: $M$. erythroloma. J: Phaseolus vulgaris var. aborigineus. K: Rynchosia edulis. L: Zornia contorta. M: R. edulis (en flor sin visitar). $\mathbf{N}$ : detalle de M (se observa la membrana desprendida espontáneamente). O: $D$. incanum (en flor sin visitar). P: detalle de O (se observa una fisura de la membrana). Los recuadros indican la zona ampliada. 
polen se deposita en forma esternotriba. Estas cuatro especies presentan hercogamia en estadío de botón floral y de flor abierta. Al comparar la distancia antera-estigma entre el estadio de botón floral y de flor abierta, se encontraron diferencias significativas en $C$. chaco-serranensis $(\mathrm{T}=-2.93$; $\mathrm{P}=0.0078)$ y $C$. stipularia $(\mathrm{T}=-3.04 ; \mathrm{P}=0.006)$.

\section{Discusión}

En este trabajo se estudió detalladamente la morfología del androceo y el gineceo de 17 especies de Papilionoideae nativas del Valle de Lerma (Salta) y su relación con los mecanismos de polinización y el sistema reproductivo. Las especies estudiadas presentan los estambres fusionados formando un tubo o columna estaminal. Algunos autores han propuesto que esta fusión limitaría el rango de polinizadores que pueden acceder a las recompensas florales (Polhill et al., 1981; Westerkamp, 1997). Esta característica floral, al igual otras como las fusiones y esculturaciones de la corola constituirían evidencias de la especialización fenotípica (sensu Ollerton et al., 2007) de las Papilionoideae a la polinización por Hymenoptera (Arroyo, 1981; Alemán et al., 2017; Figueroa Fleming \& Etcheverry, 2017). Otros autores proponen que esta característica estaría más asociada a mecanismos de polinización específicos según lo demostrado en algunas especies del género Desmodium (Tucker, 2003; Alemán et al., 2014).

La mayoría de las especies estudiadas presentan androceo diadelfo o pseudomonadelfo con fenestras basales. Se ha sugerido que este tipo de androceo estaría presente en aquellas especies que ofrecen néctar como recompensa (Rodríguez-Riaño et al., 1999b), lo cual se condice con la presencia de nectarios intraestaminales en las especies analizadas en el presente trabajo (Etcheverry et al., 2012). Por el contrario, aquellas que presentan androceo monadelfo y pseudomonadelfo sin fenestras basales no evidencian producción de néctar, como $Z$. contorta y las especies del género Desmodium (Etcheverry et al., 2012; Alemán et al., 2014). Sin embargo, se ha registrado al menos un caso de una especie con androceo monadelfo que produce néctar a través de un nectario extraestaminal (Retama sphaerocarpa; López et al., 1999).

En todas las especies estudiadas se diferencian dos verticilos de estambres, externo e interno, con anteras isomorfas de forma predominantemente orbicular o suborbicular. Solo las especies del género Crotalaria y Z. contorta presentaron anteras dimorfas. Algunos autores proponen que las especies con anteras dimorfas presentan una separación en la función de ambos verticilos. De tal manera que el polen de las anteras del verticilo externo tendría función alimenticia, mientras que las del verticilo interno tendrían una función en el mecanismo de polinización. Éstas actuarían empujando hacia afuera el polen de las anteras del verticilo externo depositado en el extremo apical de la quilla (Paulino et al., 2016). Por otro lado, se observó que las anteras tienen una inserción de tipo basifija en la mayoría de las especies estudiadas en el presente trabajo. Sólo las especies de los géneros Crotalaria y $Z$. contorta mostraron inserción de tipo dorsifija en el verticilo interno de estambres. En relación a esto, Rodríguez-Riaño et al. (1999a) proponen que las anteras del verticilo interno con inserción dorsifija presentarían una mayor versatilidad en su movimiento, favoreciendo el empuje del polen. En este sentido, serían necesarios futuros estudios que determinen la función de cada verticilo en el mecanismo de polinización y sus implicancias en el sistema reproductivo de las especies con anteras dimorfas.

La forma del estilo fue muy variada entre los diferentes géneros, siendo la forma linear curvada desde la base la más frecuente, seguida de las formas linear angular y linear curvada desde el ápice. Esta característica podría estar relacionada con el mecanismo de polinización (Rodríguez-Riaño et $a l ., 1999$ a), ya que en algunas especies el estilo se expone junto con la columna de androceo en cada visita del polinizador, o, en el caso de Desmodium, colaboraría en desencadenar el mecanismo (Alemán et. al., 2014).

Todas las especies estudiadas presentan tricomas rodeando la superficie estigmática. De acuerdo a algunos autores, esta característica evitaría que el polen propio se deposite sobre el estigma durante las primeras etapas de la antesis (Arceo \& Gómez, 2009; Drewes \& Gamba, 2011; Alemán et al., 2014). En P. vulgaris var. aborigineus y en las tres especies de Crotalaria se registraron dos tipos de tricomas según su posición: introrsos y extrorsos, los cuales presentaron diferente longitud. En las tres especies de Crotalaria, los tricomas 


\section{M. Alemán et al. - Diversidad de androceo y gineceo de especies de Papilionoideae}

más cortos se ubicaron en posición ventral hacia el estambre vexilar. En P. vulgaris var. aborigineus los tricomas periestigmáticos ventrales serían más largos para impedir el acceso del polen autógamo proveniente de los estambres cercanos al estigma en estadio de botón floral, característico de las especies asimétricas como sucede en $C$. caracalla (Etcheverry et al., 2008).

El cepillo estilar registrado en $M$. erythroloma, M. gibbosifolium y $P$. vulgaris var. aborigineus constituiría una característica relacionada directamente con la presentación secundaria de polen y con el mecanismo de polinización (Etcheverry et al., 2012). Su función sería la de arrastrar los granos de polen hacia el exterior de la quilla para su posterior contacto con el cuerpo del polinizador. Similares observaciones fueron realizadas en especies de Ancistrotropis, Cochliasanthus, Condylostylis, Leptospron, Phaseolus y Vigna (Hoc \& Amela García, 1998, 1999; Etcheverry et al., 2008; Drewes \& Gamba, 2011). En las especies de Crotalaria la presencia del cepillo estilar está relacionada con la presentación secundaria de polen, y podría estar relacionada con el mecanismo de polinización. Esto último requiere estudios más profundos en esas especies que relacionen la biología floral con el comportamiento de los polinizadores.

En la mayoría de las especies que hemos estudiado, se observó la presencia de una membrana que cubre la superficie estigmática, excepto en las del género Crotalaria. En I. sufructicosa, D. subsericeum, D. uncinatum y D. pachyrrhizum, la membrana permaneció intacta hasta el final del ciclo en las flores que no recibieron visitas. Esto sugeriría que la misma sólo puede romperse al recibir la visita de un polinizador y constituiría una estrategia para evitar la autopolinización, impidiendo que los granos de polen autógamo se adhieran al estigma y germinen (Galloni et al., 2007; Costa et al., 2014). Sin embargo, esto no se aplicaría para todas las especies con membrana estigmática rugosa, ya que tanto en $D$. incanum e I. parodiana al igual que en aquellas especies con membrana lisa se observó la ruptura espontánea de la misma al final del ciclo floral, en ausencia de visitas, permitiendo el depósito de granos de polen autógamo. Esto también fue descrito en al menos otras 12 especies de Papilionoideae con membrana (Lord \& Heslop-Harrison, 1984; Heenan, 1998; Etcheverry et al., 2008; Aronne et al., 2012; Costa et al., 2014). La ruptura espontánea de la membrana podría estar relacionada con una disminución en el grosor de la misma durante la antesis, o la presencia de microcanales transversales que permitirían la secreción de sustancias favoreciendo la adhesión del grano de polen sobre la superficie estigmática (Basso Alves et al., 2011). Según Costa et al. (2014), en algunas especies la acumulación de exudados por debajo de la cutícula permite la ruptura y la germinación subsecuente de los granos de polen compatibles. En relación a esto, consideramos que serían necesarios estudios más profundos sobre las características del estigma a fin de determinar las causas que producirían la ruptura espontánea de la membrana estigmática en estas especies.

En las tres especies de Macroptilium, se observó en la parte distal del estilo un aplanamiento dorsiventral coincidente con la torsión del estilo hacia la izquierda, esta zona es llamada éntasis por Shivanna \& Owens (1989), y sería una característica común en seis tribus de Papilionoideae, incluyendo Phaseoleae (Lavín \& Delgado, 1990). Este aplanamiento lateral o dorsiventral en la parte superior del estilo podría proporcionar refuerzo físico a la columna estaminal en el punto de flexión del pistilo y del androceo (Owens \& Stirton, 1989). Esta observación fue confirmada también en $C$. caracalla (Etcheverry et al., 2008). Acompañando este aplanamiento dorsiventral en $M$. erythroloma y $M$. gibbosifolium, se produce una torsión del estilo sobre su mismo eje acompañando la forma de la quilla, lo cual permite depositar el polen en el cuerpo de los polinizadores de forma pleurotriba, una forma de deposición poco frecuente en las especies simpátricas que coflorecen (Obs. pers.). Esta variación en la ubicación del polen en el cuerpo del polinizador, permitiría minimizar la deposición de polen heteroespecífico en el estigma (Huang et al., 2015).

En todas las especies estudiadas se registró separación espacial entre las anteras y el estigma (hercogamia), y en la mayoría el estigma se ubica por encima de las anteras, excepto en $G$. latisiliqua. De esta manera, cuando se acciona el mecanismo de polinización, el primero en entrar en contacto con el cuerpo del polinizador sería el estigma (Barrett et al., 2000). Además, esta característica impediría la deposición de polen propio favoreciendo la polinización cruzada (Webb \& Lloyd, 1986), lo que fue confirmado en otras 
especies de Papilionoideae (Kang \& Zhang, 2004; Solomon Raju \& Purnachandra-Rao, 2006). Por otro lado, la mayoría de las especies son homógamas. La maduración simultánea del androceo y gineceo en estadío de botón floral, podría suponer altos niveles de autopolinización espontánea temprana. Sin embargo, la hercogamia registrada y la presencia de la membrana estigmática intacta en estadio de botón floral, constituirían estrategias para evitar la autopolinización espontánea temprana. Sólo las especies del género Crotalaria y $Z$. contorta son dicógamas, en las que las anteras oblongas están dehiscentes antes de que el estigma esté receptivo (protandras). Además, se observó que presentan hercogamia en estadío de botón floral y de flor abierta, estas dos características constituirían estrategias para evitar la autopolinización espontánea (Galloni et al., 2007).

A pesar de todas las estrategias encontradas en las especies estudiadas en este trabajo, como la dicogamia, hercogamia, presencia de tricomas periestigmáticos y membrana estigmática, se registraron en muchas de ellas distintos niveles de autopolinización espontánea (Alemán, 2014). Esto podría explicarse por dos estrategias: la reducción de la hercogamia hacia el final del ciclo floral y/o la ruptura espontánea de la membrana estigmática en algunas especies. Estas dos estrategias favorecerían la autopolinización en ambientes impredecibles, en los que la disponibilidad de polinizadores podría verse reducida (Alemán, 2014).

El presente trabajo aporta información detallada sobre la morfología y otras características del androceo y gineceo de algunas Papilionoideae que podría ser utilizada para comprender mejor la biología reproductiva en esta subfamilia. Hasta el presente se han realizado numerosos estudios sobre la biología reproductiva de las Papilionoideae, particularmente sobre los mecanismos de polinización. Sin embargo, gran parte de éstos se han enfocado en el análisis del funcionamiento de las piezas de la corola. En este contexto, sería importante estudiar si el androceo y el gineceo constituyen o no una unidad funcional que desempeña un papel en los mecanismos de polinización. Creemos que es necesaria la realización de estudios que integren datos de la biología floral con datos de los ensambles de polinizadores y su comportamiento para comprender mejor la ecología y evolución de un linaje de especies con una gran diversidad de formas de vida, de morfología floral, de polinizadores y una amplia distribución geográfica como lo es la subfamilia Papilionoideae.

\section{Contribución DE LOS AUTORES}

MMA diseñó y realizó la investigación como parte de su tesis doctoral. DLS, CG y CY colaboraron en el trabajo de campo, interpretación de los datos y en la redacción del manuscrito final.

\section{Agradecimientos}

Los autores agradecen los invaluables aportes y sugerencias de dos revisores anónimos que contribuyeron a mejorar significativamente este artículo. A la Dra. Ángela Etcheverry y al Dr. Pablo Ortega-Baes por sus aportes. A la Ing. Silvia Blanco e Ing. Pedro Villagrán por la buena predisposición al tomar las fotos en el MEB. Este estudio se realizó con fondos otorgados por la Secretaría de Políticas Universitarias (Becas PROFITE y PROMAGRO de MMA) y el Consejo de Investigaciones de la UNSa (Proyectos CIUNSa 2120 y 2196).

\section{Bibliografía}

AGOSTINI, K., M. SAZIMA \& I. SAZIMA. 2006. Bird pollination of explosive flowers while foraging for nectar and caterpillars. Biotropica 38: 674-678. https://doi.org/10.1111/j.1744-7429.2006.00191.x

ALEMÁN, M. M. 2014. Biología floral, mecanismos de polinización y sistema reproductivo de Papilionoideas nativas del Valle de Lerma (Salta). Tesis Doctoral. Universidad Nacional de Salta, Argentina.

ALEMÁN, M. M., T. FIGUEROA-FLEMING, A. ETCHEVERRY, S. SÜHRING \& P. ORTEGABAES. 2014. The explosive pollination mechanism in Papilionoideae (Leguminosae): an analysis with three Desmodium species. Pl. Syst. Evol. 300: 177186. https://doi.org /10.1007/s00606-013-0869-8

ALEMÁN, M. M., P. HOC, D. LOPEZ-SPAHR., C. YÁÑEZ \& C. GÓMEZ. 2017. Fusión, esculturas y ornamentaciones de las piezas de la corola de 17 especies de Papilionoideae. Bol. Soc. Argent. Bot. 52: 623-646.

http://dx.doi.org/10.31055/1851.2372.v52.n4.18842 


\section{M. Alemán et al. - Diversidad de androceo y gineceo de especies de Papilionoideae}

ARCEO-GÓMEZ, G., M. L. MARTÍNEZ, V. PARRA-TABLA \& J. G. GARCÍA-FRANCO. 2011. Anther and stigma morphology in mirrorimage flowers of Chamaecrista chamaecristoides (Fabaceae): implications for buzz pollination. Plant Biol. 13: 19-24. https://doi.org/10.1111/j.14388677.2010.00324.x

ARONNE, G., M. GIOVANETTI, M. R. GUARRACINO \& V. MICCO. 2012. Foraging rules of flower selection applied by colonies of Apis mellifera: ranking and associations of floral sources. Funct. Ecol. 26: 1186-1196. https://doi.org/10.1111/j.1365-2435.2012.02017.x

ARROYO, M. T. K. 1981. Breeding systems and pollination biology in Leguminosae. In: POLHILL, R. M. \& P. H. RAVEN (eds.), Advances in Legume Systematics Part 2, pp. 723-769. Royal Botanic Gardens, Kew.

BARRETT, S. C. H. 2002. Sexual interference of the floral kind. Heredity 88: 154-159. https://doi.org/10.1038/sj/hdy/6800020

BARRETT, S. C. H. 2010. Understanding plant reproductive diversity. Philos. Trans. Roy. Soc. Lond. B. Biol. Sci. 365: 99-109. https://doi.org/10.1098/rstb.2009.0199

BARRETT, S. C. H., L. K. JESSON \& A. M. BAKER. 2000. The evolution and function of stylar polymorphisms in flowering plants. Ann. Bot. 85: 253-265. https://doi.org/10.1006/anbo.1999.1067

BASSO-ALVES, J. P., K. AGOSTINI \& S. PÁDUATEIXEIRA. 2011. Pollen and stigma morphology of some Phaseoleae species (Leguminosae) with different pollinators. Plant Biol. 13: 602-610. https://doi.org/10.1111/j.1438-8677.2010.00416.x

BIANCHI,A. R.\& C.E. YÁÑEZ. 1992.Las precipitaciones en el Noroeste Argentino. INTA, Salta.

BIANCHI, A. R. 1996. Temperaturas medias estimadas para la región Noroeste de Argentina. INTA, Salta.

BYSTRICKY, M., R. SCHULTZEKRAFT \& M. PETERS. 2010. Studies on the pollination biology of the tropical forage legume shrub Cratylia argentea. Trop. Grasslands 44: 246-252.

CABRERA, A. L. 1976. Regiones fitogeográficas Argentinas. Fasc. 1. In: KUGLER, W. F. (ed.), Enciclopedia Argentina de Agricultura y Jardinería, pp. 1-85. ACME, Buenos Aires.

COSTA, M. F. B., J. V. PAULINO, C. R. MARINHO, V. G. LEITE, G. D. PEDERSOLI \& S. P. TEIXEIRA. 2014. Stigma diversity in tropical legumes with considerations on stigma classification. Bot. Rev. 80: 1-29. https://doi.org/10.1007/s12229-014-9131-5
D'AMBrogio DE ARGÜESO, A. 1986. Manual de técnicas en histología vegetal. Hemisferio Sur, Buenos Aires.

DAFNI, A. 1992. Pollination ecology. A practical approach. Oxford University Press, Oxford.

Drewes, S. I. 2005. Morfología de estilos y estigmas en Macroptilium (Fabaceae). Kurtziana 31: 29-38.

DREWES, S. I. \& C. GAMBA. 2011. Morfología profunda del gineceo en Vigna (Leguminosae, Papilionoideae). Kurtziana 36:55-67.

DREWES, S. I. \& P. S. HOC. 2000. Morfología y desarrollo de flores cleistógamas en Macroptilium fraternum (Fabaceae). Kurtziana 28: 229-238.

ETCHEVERRY, A. V., S. M. PÉREZ DE BIANCHI \& D. MARTÍN MONTIEL DE LÓPEZ. 1999. Floral biology of Macroptilium erythroloma (L.) Urban (Fabaceae). Beitr. Biol. Pflanzen 71: 403- 418.

ETCHEVERRY, A. V., J. J. PROTOMASTRO \& C. WESTERKAMP. 2003. Delayed autonomous self-pollination in the colonizer Crotalaria micans (Fabaceae: Papilionoideae). Pl. Syst. Evol. 239: 15-28. https://doi.org/10.1007/s00606-002-0244-7

ETCHEVERRY, A. V., M. M. ALEMÁN \& T. FIGUEROA FLEMING. 2008. Flower morphology, pollination biology and mating system of the complex flower of Vigna caracalla (Fabaceae: Papilionoideae). Ann. Bot. 102: 305-316. https://doi.org/10.1093/aob/mcn106

ETCHEVERRY, A. V., M. M. ALEMAN, T. FIGUEROA-FLEMING, D. LÓPEZ-SPAHR, C. A. GÓMEZ, C. YAÑEZ \& P. ORTEGA-BAES. 2012. Pollen: ovule ratio and its relationship with other floral traits in Papilionoideae (Leguminosae): an evaluation with Argentine species. Pl. Biol. 14: 171-178. https://doi.org/10.1111/j.1438-8677.2011.00489.x

FAIGÓN SOVERNA, A., B. GALATI \& P. HOC .2003. Study of ovule and megagametophyte development in four species of subtribe Phaseolinae (Leguminosae). Acta Biol. Crac. Ser. Bot. 42: 6373.

FIGUEROA FLEMING, T. 2014. Interacciones plantapolinizador en Papilionoideas (Leguminosae) simpátricas nativas de Salta, Argentina. Tesis Doctoral. Universidad Nacional de Salta, Argentina.

FIGUEROA FLEMING, T. \& Á. V. ETCHEVERRY. 2017. Comparing the efficiency of pollination mechanisms in Papilionoideae. Arthropod-Plant Interac. 11: 273-283. https://oi.org/10.1007/s11829-017-9515-7 
FRANKLIN-TONG, V. E. 2008. Self-incompatibility in flowering plants: Evolution diversity, and mechanisms. Springer, Berlin.

https://doi.org/10.1007/978-3-540-68486-2

GALLONI, M., L. PODDA, D. VIVARELLI \& G. CRISTOFOLINI. 2007. Pollen presentation, pollen-ovule ratios, and other reproductive traits in Mediterranean Legumes (Fam. Fabaceae-Subfam. Faboideae). Pl. Syst. Evol. 266: 147-164. https://doi.org/10.1007/s00606-007-0526-1

GALLONI, M., L. PODDA, D. VIVARELLI, M. QUARANTA \& G. CRISTOFOLINI. 2008. Visitor diversity and pollinator specialization in Mediterranean legumes. Flora 203: 94-102. https://doi.org/10.1016/j.flora.2006.12.006

GRÜNMEYER, R. 1990. Pollination by bats and nonflying mammals of the african tree Parkia bicolor (Mimosaceae). Mem. New York Bot. Gard. 55: 83104.

HEENAN, P. B. 1998. The pollination system and stigmatic cuticle of Clianthus puniceus (Fabaceae). New Zealand J. Bot. 36: 311-314. https://doi.org/10.1080/0028825X.1998.9512571

HESLOP-HARRISON, J. \& Y. HESLOP-HARRISON. 1985. Surfaces and secretions in the pollen-stigma interaction: a brief review. J. Cell Sci.1985: 287-300. https://doi.org/10.1242/jcs.1985.Supplement_2.15

HOC, P. S., V. DI STILIO, M. AGULLÓ, M. BRIZUELA \& R. PALACIOS. 1993. Biología floral de Vigna longifolia (Legminosae, Phaseolae). Darwiniana 32: 27-39.

HOC, P. S., M. A. AGULLÓ \& R. A. PALACIOS.1994. Stylar trimorphism in four functionally andromonoecious Prosopis species (Mimosaceae). Pl. Syst. Evol. 190: 143-156. https://doi.org/10.1007/BF00986190

HOC, P. S. \& M. T. AMELA GARCÍA. 1998. Floral biology and reproductive system of Phaseolus augusti (Fabaceae). Beitr. Biol. Pflanzen 70: 121140.

HOC, P. S. \& M. T. AMELA GARCÍA. 1999. Biología floral y sistema reproductivo de Phaseolus vulgaris var. aborigeneus (Fabaceae). Revista Biol. Trop. 47: 59-67.

HOC, P. S., S. DREWES \& M. T. AMELA GARCÍA. 2003. Biología floral, sistema reproductivo y éxito reproductivo de Macroptilium fraternum (Fabaceae). Revista Biol. Trop. 51: 369-380.

HUANG, Z. H., H. L. LIU \& H. Q. HUANG. 2015. Interspecific pollen transfer between two coflowering species was minimized by bumblebee fidelity and differential pollen placement on the bumblebee body. J. Plant Ecol. 8: 109-115.

https://doi.org/10.1093/jpe/rtv015

INFOSTAT. 2016. Grupo InfoStat. FCA. Universidad Nacional de Córdoba, Argentina.

KANG, Y. \& M. L. ZHANG. 2004. Study of pollen brush in selected species of Astragalus L. subgenus Pogonophace Bunge (Leguminosae). Pl. Syst. Evol. 249: 1-8. https://doi.org/10.1007/s00606-004-0174-7

KEARNS, C. A. \& D. W. INOUYE. 1993. Techniques for pollination biologists. University Press of Colorado, Niwot.

LAVIN, M. \& A. DELGADO. 1990. Pollen brush of Papilionoideae (Leguminosae): morphological variation and systematic utility. Amer. J. Bot. 77: 1294-1312. https://doi.org/10.1002/j.1537-2197.1990.tb11381.x

LLOYD, D. G., C. J. WEBB. 1986. The avoidance of interference between the presentation of pollen and stigmas in angiosperms I. Dichogamy. New Zealand J. Bot. 24: 135-162. https://doi.org/10.1080/0028825X.1986.10409725

LÓPEZ, J., T. RODRÍGUEZ-RIAÑO, A. ORTEGAOLIVENCIA, J. A DEVESA \& T. RUIZ. 1999. Pollination mechanisms and pollen-ovule ratios in some Genisteae (Fabaceae) from Southwestern Europe. Pl. Syst. Evol. 216: 23-47. https://doi.org/10.1007/BF00985099

LORD, E. \& Y. HESLOP-HARRISON. 1984. Pollen and stigma organization in Leguminosae: stigma organization and the breeding system of Vicia faba. Ann. Bot. 54: 827-836. https://doi.org/10.1093/ oxfordjournals.aob.a086856

LPWG. 2017. A new subfamily classification of the Leguminosae based on a taxonomically comprehensive phylogeny. Taxon 66: 44-77. https://doi.org/10.12705/661.3

OLLERTON, J., A. KILLICK, E. LAMBORN, S. WATTS \& M. WHISTON. 2007. Multiple meanings and modes: on the many ways to a generalist flower. Taxon 56: 717-728. https://doi.org/10.2307/25065855

OWENS, S.J. \& C.H. STIRTON. 1989. Pollen, stigma and style interactions in the Leguminosae. In: STIRTON, C. H., J. L. ZARUCCHI (eds.), Advances in legume biology, pp. 105-112. Monographs in Systematic Botany from the Missouri Botanical Garden, St. Louis. 


\section{M. Alemán et al. - Diversidad de androceo y gineceo de especies de Papilionoideae}

PAULINO, J. V., V. F. MANSANO \& G. PRENNER. 2016. Evidence for division of labor and division of function related to the pollen release in Papilionoideae (Leguminosae) with a heteromorphic androecium. Int. J. Plant. Sci. 177: 590-607. https://doi.org/10.1086/687351

POLHILL, R. M., P. H. RAVEN \& C. H. STIRTON. 1981. Evolution and systematics of the Leguminosae. In: POLHILL, R. M. \& P. H. RAVEN (eds.), Advances in Legume Systematics Part 2, pp. 1-26. Royal Botanic Gardens, Kew.

RODRÍGUEZ-RIAÑO, T., A. ORTEGA-OLIVENCIA \& J. A. DEVESA. 1999a. Biología floral en Fabaceae. Ruizia 16: 1-176.

RODRÍGUEZ-RIAÑO, T., A. ORTEGA-OLIVENCIA \& J. A. DEVESA. 1999b. Types of Androecium in the Fabaceae of SW Europe. Ann. Bot. 83: 109-116. https://doi.org/10.1006/anbo.1998.0808

SHIVANNA, K. R., \& S. J. OWENS. 1989. Pollen pistil interactions (Papilionoideae). In: STIRTON, C. H., J. L. ZARUCCHI (eds.), Advances in legume biology, pp. 157-182. Monographs in Systematic Botany from the Missouri Botanical Garden, St. Louis.

SOLOMON RAJU, A. J. \& S. PURNACHANDRARAO. 2006. Explosive pollen release and pollination as a function of nectar feeding activity of certain bees in the biodiesel plant, Pongamia pinnata (L.) Pierre (Fabaceae). Curr. Sci. 90: 960-967.

STEVENS, P. F. 2001. Angiosperm Phylogeny Website. Version 14 [online]. Disponible en: http://www. mobot.org/MOBOT/research/APweb/ [Acceso: 12 Junio 2020]

SUZUKI, N. 2003. Significance of flower exploding pollination on the reproduction of the Scotch broom, Cytisus scoparius (Leguminosae). Ecol. Res. 18: 523-532. https://doi.org/10.1046/j.1440-1703.2003.00575.x

TUCKER, S. C. 1987. Floral initiation and development in legumes. In: STIRTON, C. H. (ed.), Advances in Legume Systematics Part 3, pp. 183-239. Royal Botanic Gardens, Kew.
TUCKER, S. C. 1988a. Heteromorphic flower development in Neptunia pubescens (Leguminosae: Mimosoideae). Amer. J. Bot. 75: 204-224. https://doi.org/10.1002/j.1537-2197.1988.tb13432.x

TUCKER, S. C. 1988b. Dioecy in Bauhinia resulting from organ suppression. Amer. J. Bot. 75: 1584-1597. https://doi.org/10.1002/j.1537-2197.1988.tb11232.x

TUCKER, S. C. 1989. Overlapping organ initiation and common primordia in flowers of Pisum sativum (Leguminosae: Papilionoideae). Amer. J. Bot. 76: 714-729.

https://doi.org/10.1002/j.1537-2197.1989.tb11366.x

TUCKER, S. C. 1990. Loss of floral organs in Ateleia (Leguminosae: Papilionoideae: Sophoreae). Amer. J. Bot. 77: 750-761. https://doi.org/10.1002/j.1537-2197.1990.tb14465.x

TUCKER, S. C. 1991. Helical floral organogenesis in Gleditsia, a primitive Caesalpinioid legume. Amer. J. Bot. 78: 1130-1149.

https://doi.org/10.1002/j.1537-2197.1991.tb14520.x

TUCKER, S. C. 1992. The developmental basis for sexual expression in Ceratonia siliqua (Leguminosae: Caesalpinioideae: Cassieae). Amer. J. Bot. 79: 318327.

https://doi.org/10.1002/j.1537-2197.1992.tb14555.x

TUCKER, S. C. 2003. Floral development in legumes. Pl. Physiol. 131: 911-926. https://doi.org/10.1104/ pp.102.017459

ULIBARRI, E. 2008. Los géneros de Caesalpinioideae (Leguminosae) presentes en Sudamérica. Darwiniana 46: 66-163. https://doi.org/10.14522/darwiniana.2014.461.286

WEBB, C. J. \& D. G. LLOYD. 1986. The avoidance of interference between the presentation of pollen and stigmas in angiosperms II. Herkogamy. New Zealand J. Bot. 24: 163-178. https://doi.org/10.1080/0028825X.1986.10409726

WESTERKAMP, C. 1997. Keel blossoms: bee flowers with adaptations against bees. Flora 192: 125-132. https://doi.org/10.1016/S0367-2530(17)30767-3

YEO, P. F. 1993. Secondary pollen presentation. Form, function and evolution. Springer, New York. 
